\title{
Clinical predictors and outcome of bowel resection in paediatric intussusception
}

\author{
Akinlabi E Ajao1, Taiwo A Lawal², Olakayode O Ogundoyin², Dare I Olulana²
}

1. Department of Surgery, Bowen University Iwo and Bowen University Teaching Hospital, Ogbomoso, Nigeria

2. Department of Surgery, University of Ibadan and University College Hospital, Ibadan

\begin{abstract}
Introduction: Surgery remains the mainstay in treating intussusception in developing countries, with a correspondingly high bowel resection rate despite a shift to non-operative reduction in high-income countries.

Objective: To assess factors associated with bowel resection and the outcomes of resection in childhood intussusception.

Methods: A review of children with intussusception between January 2006 and December 2015 at the University College Hospital, Ibadan, Nigeria. The patients were categorized based on the need for bowel resection and analysis done using the SPSS version 23.

Results: 121 children were managed for intussusception during this period. $53(43.8 \%)$ had bowel resection, 61 (50.4\%) did not require resection and $7(5.8 \%)$ were unknown. 40 (75.5\%) of the resections were right hemi-colectomy. The presence of fever, abdominal pain, distension, rectal mass, age $<12$ months, heart rate $>145 / \mathrm{min}$ and duration of symptoms $>2$ days were associated with the need for bowel resection $(\mathrm{p}<0.05)$. However, only age and abdominal pain independently predicted need for resection. Bowel resection was more associated with development of post-operative complications and prolonged hospital stay $(\mathrm{p}<0.05)$.

Conclusion: Infants presenting with abdominal pain and abdominal distension after two days of onset of symptoms were more likely to require bowel resection. Resection in intussusception significantly increased post-operative complications and length of hospital stay.
\end{abstract}

Keywords: Paediatric intussusception; bowel resection; developing countries.

DOI: https://dx.doi.org/10.4314/ahs.v20i3.52

Cite as: Ajao AE, Lawal TA, Ogundoyin OO, Olulana DI. Clinical predictors and outcome of bowel resection in paediatric intussusception. Afri Health Sci. 2020;20(3): 1463-1470. https:/ / dx.doi.org/10.4314/abs.v20i3.52

\section{Introduction}

Intussusception remains the most common cause of acute abdominal pain and intestinal obstruction in infants and toddlers ${ }^{1-3}$. The aetiology in children is mainly idiopathic but may be influenced by anatomic and infectious factors ${ }^{1,4}$. Non-operative management using pneumatic or hydrostatic reduction under fluoroscopy or ultrasound guidance is now the treatment of choice in this condition with a reported success rate of $85-90 \%$ ${ }^{4}$. This modality is, however, absolutely contraindicated in the presence of peritonitis, signs of bowel necrosis

\section{Corresponding author: \\ Akinlabi E Ajao \\ Department of Surgery, Bowen University, \\ Iwo and Bowen University Teaching Hospital, \\ Ogbomoso, Nigeria \\ G.P.O Box 1749, Dugbe, Ibadan, Nigeria \\ +2348032802484 \\ Email address: akinlabi.ajao@gmail.com}

and evidence of a pathologic lead point ${ }^{3-5}$. Surgical treatment is, therefore, indicated when non-operative reduction is contraindicated or unsuccessful ${ }^{3,4}$. Factors that may be associated with failure of non-operative reduction include: symptoms $>48$ hours, haematochezia, abdominal distension, poor prognostic signs on ultrasound, failure of initial enema and the use of hydrostatic enema (versus pneumatic reduction) ${ }^{6,7}$.

Surgical treatment of intussusception may involve manual reduction only or resection of the bowel in the presence of bowel necrosis, perforation or irreducibility. Surgical intervention for intussusception tends to be low in specialist paediatric surgery centers with facilities for pneumatic or hydrostatic reduction ${ }^{2,8}$. However, the surgery rate remains high in many developing countries, ranging from $74-100 \%$ in some reports ${ }^{9-13}$. This has generally been due to delayed presentation from ignorance of parents and/or delayed referral from peripheral hospitals ${ }^{10,12-14}$. Specialist paediatric surgical care and radiological facilities and expertise for non-surgical reductions have also been limited in these settings and 
these may have been contributory factors. Bowel resection rates in childhood intussusception in developing countries have been correspondingly high, reportedly ranging from $41-68 \%{ }^{9,10,12}$. There is, in turn, a higher morbidity and mortality reported among these cases.

The aim of this study was to evaluate clinicopathologic predictors and outcomes of bowel resection in childhood intussusception in a tertiary health center in a middle-income country.

\section{Methods}

This was a retrospective descriptive study, in which the medical records of all patients below the age of 15 years admitted with radiological or surgical diagnosis of intussusception between January 2006 and December 2015 at the University College Hospital, Ibadan, Nigeria were reviewed. Ethical approval was obtained from the UI/UCH Joint Ethics Review Committee.

Data were collected on age, sex, symptoms, indications for resection, type of bowel resection performed, complications after surgery and the length of hospital stay. The patients were categorized into a resection group and a non-resection group based on the need for eventual bowel resection as the definitive treatment.

Categorical variables were summarized using frequencies, rates, ratios and proportions, and continuous variables using mean and standard deviations or median and range, depending on the distribution of the data. The heart rate was obtained as continuous variable but was then categorized into a binary variable using the mean heart rate before further analysis.

Bivariate analyses assessing factors related to bowel resection in childhood intussusception were done using binary logistic regression. Those factors that were found to have statistically significant associations were then included in a stepwise logistic regression analysis to assess the independent predictors of bowel resection in this cohort.

The primary outcome measure was the treatment endpoint of resection or non-resection, whereas the secondary outcome measures were the post-operative complication rate, length of hospital stay and the mortality rate. The association between treatment with bowel resection and the 30-day and long-term post-operative complication rates were measured using the chi square statistic and the association with mortality was assessed using the Fisher's exact test. The Mann-Whitney U test was used to test the association between bowel resection and the length of hospital stay of the patients.

The level of significance was set as $\mathrm{p}<0.05$. Data was collated and analyzed using the IBM Statistical Package for Social Sciences (SPSS software version 23).

\section{Results}

A total of 121 cases of childhood intussusception were recorded during the 10-year period. There were $73(60.3 \%)$ boys and $48(39.7 \%)$ girls, giving a male-tofemale ratio of 1.5:1. The median age at presentation was seven months (range: 1-109 months). Passage of bloody stool, vomiting, abdominal pain and fever were the most common presenting features in these patients [Table 1]. The median duration of symptoms was three days (range: 2 hours - 21 days). Ninety-five (78.5\%) children had surgical treatment and 18 (14.9\%) had hydrostatic reduction. Of the remaining eight children, one had spontaneous reduction, three were taken away without treatment against medical advice and four had missing information on their final treatment modality [Table 1]. These eight patients were excluded from the bivariate and multivariate analyses. Of the 95 children who had surgery, 53 (55.8\%) had bowel resection for bowel necrosis, non-reducibility and the presence of a pathologic lead point giving an overall (of all cases of intussusception) resection rate of $43.8 \%$ [Table 1]. 
Table 1. Demography, pattern of presentation, mode of treatment and indications for bowel resection among children with intussusception

\begin{tabular}{|c|c|c|}
\hline Characteristic & Frequency & Percentage \\
\hline \multicolumn{3}{|l|}{ Gender } \\
\hline Male & 73 & 60.3 \\
\hline Female & 48 & 39.7 \\
\hline \multicolumn{3}{|l|}{ Age } \\
\hline$<12$ months & 95 & 78.5 \\
\hline$\geq 12$ months & 26 & 21.5 \\
\hline \multicolumn{3}{|l|}{ Clinical features } \\
\hline Vomiting & $105 / 114$ & 92.1 \\
\hline Fever & $80 / 113$ & 70.8 \\
\hline Abdominal pain & $77 / 106$ & 72.6 \\
\hline Abdominal distension & $57 / 111$ & 51.4 \\
\hline Bloody stool & $110 / 117$ & 94.0 \\
\hline Preceding diarrhoea & $12 / 107$ & 11.2 \\
\hline Recent coryza & $17 / 70$ & 24.3 \\
\hline Abdominal mass & $66 / 113$ & 58.4 \\
\hline Palpable rectal mass & $27 / 106$ & 25.5 \\
\hline \multicolumn{3}{|l|}{ Duration of symptoms } \\
\hline$\leq 2$ days & 53 & 43.8 \\
\hline$>2$ days & 63 & 52.1 \\
\hline Missing $^{\dagger}$ & 5 & 4.1 \\
\hline \multicolumn{3}{|l|}{ Treatment } \\
\hline Hydrostatic reduction & 18 & 14.9 \\
\hline Surgery & 95 & 78.5 \\
\hline Spontaneous resolution & 1 & 0.8 \\
\hline Left against medical advice & 3 & 2.5 \\
\hline Missing $^{\dagger}$ & 4 & 3.3 \\
\hline \multicolumn{3}{|l|}{ Bowel resection } \\
\hline Yes & 53 & 43.8 \\
\hline No & 61 & 50.4 \\
\hline Missing $^{\dagger}$ & 7 & 5.8 \\
\hline \multicolumn{3}{|l|}{ Indications for bowel resection } \\
\hline Gangrene & 37 & 69.8 \\
\hline Non-reducibility & 6 & 11.3 \\
\hline Pathologic lead point & 4 & 7.5 \\
\hline Missing $^{\dagger}$ & 6 & 11.3 \\
\hline \multicolumn{3}{|l|}{ Type of resection } \\
\hline Right hemi-colectomy & 40 & 75.5 \\
\hline Ileal resection & 6 & 11.3 \\
\hline Left hemi-colectomy/colonic resection & 2 & 3.8 \\
\hline Missing $^{\dagger}$ & & \\
\hline
\end{tabular}

Right hemi-colectomy was the commonest resection performed $(40,75.5 \%)$ as a majority $(82.6 \%)$ of the patients presented with ileocolic intussusception. All anastomoses were performed using absorbable (polyglactin 910) sutures in two layers, whereas one patient, who had colocolic intussusception, had a stoma fashioned initially, which was closed after three weeks.

The proportion of children presenting with the main clinical features were consistently higher in children who eventually had bowel resection (Figure 1). Following univariate analysis, factors found to be significantly associated with eventual bowel resection were age, fever, abdominal pain, abdominal distension, rectal mass, heart rate and duration of symptoms (Table 2). Stepwise logistic regression showed that age and abdominal pain, as evidenced by child's intermittent inconsolable cry, were independently predictive of eventual intestinal resection in the children (Table 3). 


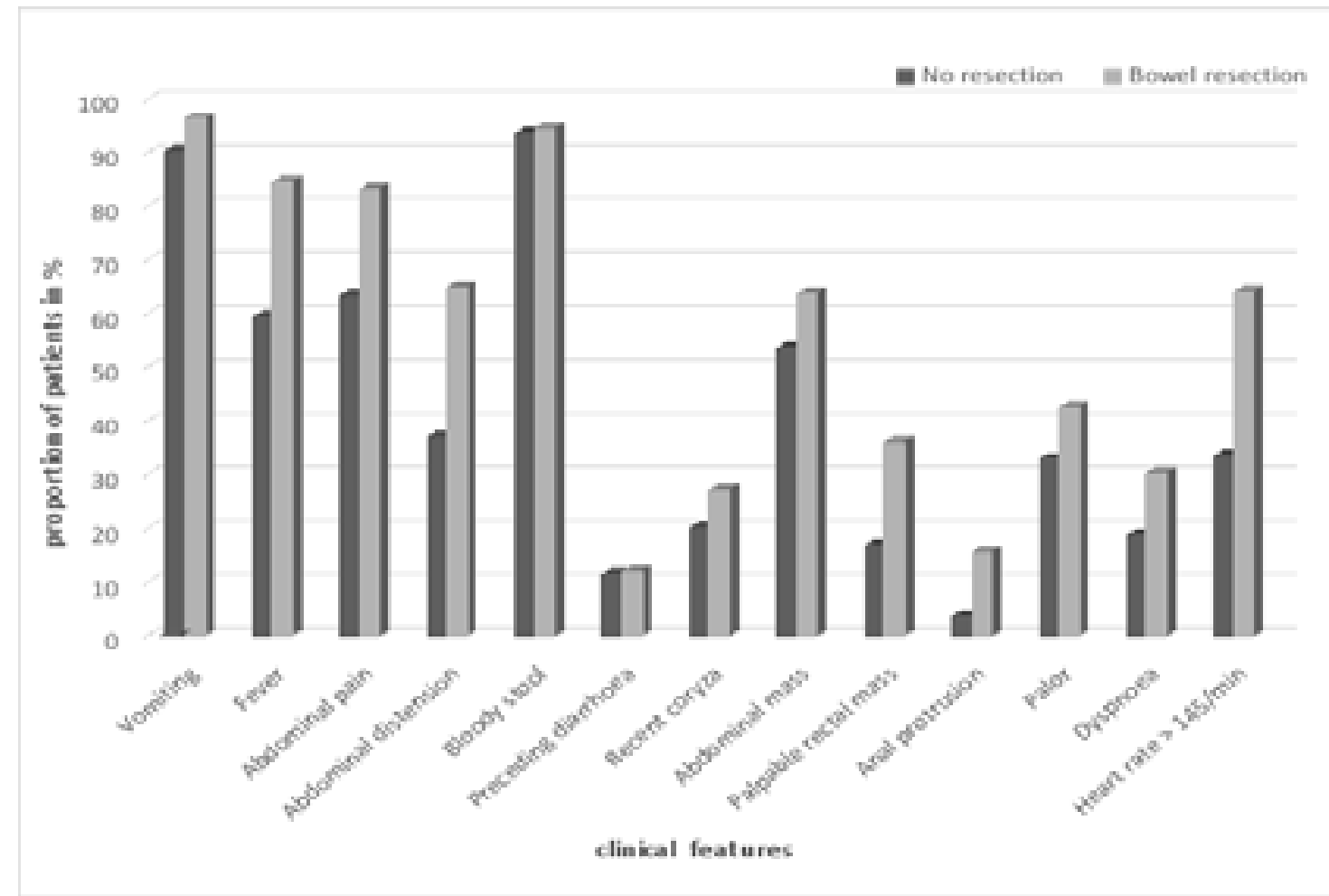

Figure 1: Comparison of presenting features between children requiring and those not requiring bowel resection

Table 2. Bivariate logistic regression analysis of factors associated with bowel resection among children with intussusception

\begin{tabular}{|c|c|c|c|}
\hline Factor & OR & $95 \%$ confidence interval & p-value \\
\hline \multicolumn{4}{|c|}{ 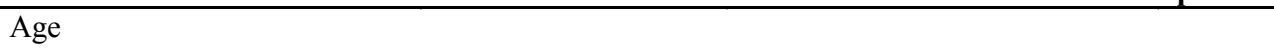 } \\
\hline $\begin{array}{l}<12 \text { months } \\
\geq 12 \text { months (Ref) }\end{array}$ & 2.75 & $1.05-7.24$ & $0.040 *$ \\
\hline \multicolumn{4}{|l|}{-10 - } \\
\hline Female & 1.83 & $0.86-3.91$ & 0.119 \\
\hline Vomiting & 2.72 & $0.53-14.12$ & 0.233 \\
\hline Fever & 3.69 & $1.47-9.21$ & $0.005 *$ \\
\hline Abdominal pain & 2.84 & $1.12-7.22$ & 0.028* \\
\hline Abdominal distension & 3.14 & $1.43-6.91$ & 0.004* \\
\hline Bloody stool & 1.17 & $0.25-5.48$ & 0.842 \\
\hline Preceding diarrhoea & 1.04 & $0.31-3.48$ & 0.944 \\
\hline Abdominal mass & 1.51 & $0.70-3.25$ & 0.289 \\
\hline Rectal mass & 2.81 & $1.12-7.06$ & $0.028 *$ \\
\hline \multicolumn{4}{|l|}{ Heart rate } \\
\hline $\begin{array}{l}\leq 145 / \min (\text { Ref }) \\
>145 / \min \end{array}$ & 3.54 & $1.31-9.55$ & $0.013 *$ \\
\hline $\begin{array}{l}\text { Duration of symptoms } \\
\leq 2 \text { days (Ref) }\end{array}$ & & & \\
\hline$>2$ days & 2.40 & $1.10-5.10$ & $0.026 *$ \\
\hline
\end{tabular}

${ }^{*} p$ value $<0.05$; OR- Odds Ratio 
Table 3. Stepwise logistic regression analysis for significant predictors of bowel resection among children with intussusception

\begin{tabular}{|c|c|c|c|}
\hline Factor & OR & $\begin{array}{l}95 \% \text { confidence } \\
\text { interval }\end{array}$ & p-value \\
\hline \multicolumn{4}{|l|}{ Age } \\
\hline$<12$ months & 3.38 & $1.11-10.33$ & 0.032 \\
\hline $\begin{array}{l}\geq \quad 12 \mathrm{mc} \\
(\mathrm{Ref})\end{array}$ & & & \\
\hline Abdominal pain & 3.91 & $1.43-10.61$ & 0.008 \\
\hline
\end{tabular}

Thirty-four $(28.1 \%)$ patients developed at least a post-operative complication within 30 days after surgery. Wound infection occurred in $16(47.1 \%)$ patients, sepsis in six $(5.0 \%)$ patients and anastomotic leakage in two $(1.7 \%)$ patients. There was a significant association between bowel resection and the development of these complications with a p-value of 0.036 (Table 4). The mean length of hospital stay was significantly longer (8.1 days versus 5.5 days, $\mathrm{p}<0.0001$ ) in those who had bowel resection in comparison with those who did not (Table 4).

Table 4. Comparison of outcome measures between bowel resection and the non-resection group in the management of childhood intussusception

\begin{tabular}{llll}
\hline Variable & Resection group & $\begin{array}{l}\text { Non-resection } \\
\text { group }\end{array}$ & p-value \\
\hline 30-day complication & $40.4 \%$ & $22.0 \%$ & $\mathbf{0 . 0 3 6 *}$ \\
30-day mortality & $9.1 \%$ & $3.2 \%$ & 0.249 \\
$\begin{array}{l}\text { Long-term } \\
\text { complication }\end{array}$ & $3.8 \%$ & $4.4 \%$ & 1.000 \\
$\begin{array}{l}\text { Length of hospital } \\
\text { stay (mean } \pm \mathrm{SD} \text { ) }\end{array}$ & $8.1( \pm 3.8)$ days & $5.5( \pm 4.3)$ days & $<\mathbf{0 . 0 0 0 1 *}$ \\
\hline $\mathrm{SD}=$ Standard deviation; ${ }^{*} p$ value significant at $<0.05$ &
\end{tabular}

Five $(9.1 \%)$ of the patients who had bowel resection died in comparison with two $(3.2 \%)$ among those who had no resection $(p=0.249)$. Of the patients who had surgery, five $(5.3 \%)$ patients re-presented with adhesive intestinal obstruction later; three of them were managed non-operatively and two, operatively. There was no statistical association between bowel resection and the development of this long-term complication $(\mathrm{p}=$ 1.000).

\section{Discussion}

Measures to reduce the bowel resection rate may be pertinent to minimizing morbidity and mortality in pae- diatric intussusception in developing countries. From previous studies, intussusception was the most common indication for bowel resection in children less than 15 years ${ }^{15,16}$. Controlling factors associated with eventual bowel resection in intussusception will therefore, significantly reduce the burden of childhood intestinal resection. In the present study, $44 \%$ of all patients with intussusception had intestinal resection and these formed $56 \%$ of the operations performed for this condition. This enormous burden is similarly reported by studies from other centres in Nigeria and other developing countries $9,10,12,13,17$. In contrast, Somme et al. reported a resection rate of $28 \%$ of operations for intussusception 
in Ontario, Canada, while surgery was required in only $25 \%$ of all cases of intussusception ${ }^{18}$.

The main indication for resection in this series was necrosis of the intussusceptum which accounted for almost $70 \%$ of the cases (Table 1). This is usually a late complication resulting from the entrapment of the mesentery of the affected part of bowel, compromising blood supply. This, therefore, implies that a significant number of our patients present late in the disease as have been previously documented in this centre ${ }^{14}$. The median duration of symptoms in the present study was three days (range: 2 hours - 21 days) and more than half of the patients presented after 48 hours of onset of observed symptoms. We, however, note that even this reported duration of symptoms may be an under-estimation, as many parents are oblivious of early symptoms, such as screaming attacks and refusal of feeds. The first "danger sign" that triggers a search for help by most mothers is the infant's passage of bloody stool. This, however, occurs late in the evolution of the disease as it is usually the last sign to occur based on its pathogenesis ${ }^{1,19}$, thus essentially meaning the infants are brought late to the hospital.

Presentation more than two days after the onset of symptoms was associated with a higher risk of intestinal resection in this study. This was in keeping with findings from other studies where prolonged duration of symptoms was associated with the need for operative management and/or bowel resection in the management of childhood intussusception ${ }^{5-7,20,21}$. Delayed presentation, either by the parents or by referring health centres, has remained a challenge in this setting ${ }^{10,14}$. Abdominal distension usually results from the dilatation of the proximal small bowel due to the distal obstruction at the point of the intussusception. Following progression of the disease, the intussusceptum may extend through the intussuscipien to become palpable within the rectum and may further prolapse through the anus. These events usually follow delay in treatment and thus, increase the risk of bowel gangrene. We found that abdominal distension and a palpable rectal mass were significantly related to the need for bowel resection. This is similar to the finding by Khorana et al., who reported that abdominal distension was a significant risk factor for failure of non-operative reduction and therefore, predicted the need for surgical management in intussusception $^{6}$. However, abdominal distension and palpable rectal mass did not independently predict the probability of intestinal resection in this series.

In the present study, age was an independent predictor of bowel resection in paediatric intussusception. Children aged less than 12 months were three times as likely as those 12 months or older to require a bowel resection at operation. We hypothesized that this may have been due to the fact that infants are more prone to developing shock, which may further compromise the already precarious blood supply to the intussusceptum. This may explain the higher number of gangrenous intussusception in these infants and the subsequent need for intestinal resection. In a similar study assessing the risk factors for the need for surgery in paediatric intussusception, age less than a year was also found to be a significant variable ${ }^{7}$. The authors, however, suggested that the probable reluctance of radiologists to attempt aggressive reduction in this age group might have accounted for that observation. While Somme et al. found no association between resections and age ${ }^{18}$, Wong et al. found an association with older age but this was related to the presence of pathologic lead points (PLPs) which was not significant in the present study ${ }^{20}$.

The presence of abdominal pain was associated with an increased risk of bowel resection and it independently predicted the need for resection (RR: 3.91; $\mathrm{p}=0.008$ ). Pain was usually characterized by intermittent screams with associated drawing up of the legs towards the abdomen. Abdominal pain, however, remains one of the classical symptoms of intussusception and occurs in a significant number of patients in whom even non-operative measures suffice. Perhaps abdominal pain becomes more significant in infants and may imply a worse prognosis as it is often less prominent in infants as against older children in whom it is the main presenting symptom ${ }^{22}$.

Bowel resection in intussusception is associated with increased morbidity and mortality in affected patients as against those who have simple manual reduction. From a previous study, length of hospital stay (LOS) was longer in those who had resection than in those who did not ${ }^{18}$. Similarly, the mean LOS for those who had resection in our study was 8.1 days compared to 5.5 days among those who did not, and this difference was statistically significant $(p<0.0001)$. The prolonged hospital stays among those who had resection will im- 
ply increase in the cost of care ${ }^{18}$. The 30 -day post-operative complication rate was also significantly higher in children who required bowel resection. Wound infection and anastomotic leak were notable complications among these patients. Long-term complications like adhesive intestinal obstruction were similar in both groups. Mortality rate among those who had bowel resection was $9.1 \%$ but the procedure was not significantly associated with the rate of mortality $(p=0.246)$. Our inability to demonstrate any statistically significant difference in long-term complications and mortality between the two groups is probably due to the heterogeneous nature of the comparison group, which included both operative and non-operative management.

A limitation this study, however, had was the presence of some missing data due its retrospective design and poor record keeping in this environment. These missing data were excluded from tests of significance in the course of the study.

\section{Conclusion}

Bowel resection remains a mainstay in the management of intussusception in this environment due to delayed presentation. Infants presenting with abdominal pain and abdominal distension after two days of onset of symptoms were more likely to require bowel resection. However, only age and abdominal pain independently predicted the risk of bowel resection. Bowel resection in intussusception is significantly associated with more post-operative complications and prolonged stay in the hospital. There is the need to educate primary care physicians to have high index of suspicion for intussusception and the need for early referral to paediatric surgical centres.

\section{Conflict of interest}

We declare no conflict of interest

\section{References}

1. Maki AC, Fallat ME. Intussusception. In: Ashcraft KW, Holcomb GW, Murphy JP, et al. (eds) Ashcraft's Pediatric Surgery. London ; New York: Saunders/Elsevier, 2014, pp. 531-538.

2. Saxena AK, Höllwarth ME. Factors influencing management and comparison of outcomes in paediatric intussusceptions. Acta Paediatr 2007; 96: 1199-1202. 3. Lehnert T, Sorge I, Till H, et al. Intussusception in children-clinical presentation, diagnosis and management. Int J Colorectal Dis 2009; 24: 1187-1192.
4. Marsicovetere P, Ivatury SJ, White B, et al. Intestinal Intussusception: Etiology, Diagnosis, and Treatment. Clin Colon Rectal Surg 2017; 30: 30-39.

5. Reijnen JA, Festen C, Van Roosmalen RP. Intussusception: factors related to treatment. Arch Dis Child 1990; 65: 871-873.

6. Khorana J, Singhavejsakul J, Ukarapol N, et al. Prognostic indicators for failed nonsurgical reduction of intussusception. Ther Clin Risk Manag 2016; 12: 1231 1237.

7. Fallon SC, Lopez ME, Zhang W, et al. Risk factors for surgery in pediatric intussusception in the era of pneumatic reduction. J Pediatr Surg 2013; 48: 1032-1036. 8. McAteer JP, Kwon S, LaRiviere CA, et al. Pediatric specialist care is associated with a lower risk of bowel resection in children with intussusception: a population-based analysis. J Am Coll Surg 2013; 217: 226-232.

9. Ogundoyin OO, Olulana DI, Lawal TA. Childhood intussusception: A prospective study of management trend in a developing country. Afr J Paediatr Surg 2015; 12: 217-220.

10. Bode CO. Presentation and management outcome of childhood intussusception in Lagos: a prospective study. Afr J Paediatr Surg 2008; 5: 24-28.

11. Ekenze SO, Mgbor SO, Okwesili OR. Routine surgical intervention for childhood intussusception in a developing country. Ann Afr Med 2010; 9: 27-30.

12. Talabi AO, Sowande OA, Etonyeaku CA, et al. Childhood intussusception in Ile-Ife: What has changed? Afr J Paediatr Surg 2013; 10: 239-242.

13. Chalya PL, Kayange NM, Chandika AB. Childhood intussusceptions at a tertiary care hospital in northwestern Tanzania: a diagnostic and therapeutic challenge in resource-limited setting. Ital J Pediatr 2014; 40: 28.

14. Ogundoyin OO, Olulana DI, Lawal TA. Childhood intussusception: Impact of delay in presentation in a developing country. Afr J Paediatr Surg 2016; 13: 166-169. 15. Ajao AE, Lawal TA, Olulana DI, et al. Bowel resection in children in Ibadan, Nigeria. J West Afr Coll Surg 2018; 8: 50-61.

16. Abdur-Rahman LO, Adeniran JO, Taiwo JO, et al. Bowel resection in Nigerian children. Afr J Paediatr Surg 2009; 6: 85-87.

17. Shakya VC, Agrawal CS, Sinha AK, et al. Childhood intussusception: a prospective institutional study at BPKIHS. J Nepal Paediatr Soc 2011; 31: 6-10.

18. Somme S, To T, Langer JC. Factors determining the need for operative reduction in children with intussusception: a population-based study. J Pediatr Surg 2006; 41: 1014-1019. 
19. Columbani PM, Scholz S. Intussusception. In: Coran AG, Adzick NS (eds) Pediatric surgery. Philadelphia, PA: Elsevier/Saunders, 2012, pp. 1093-1110.

20. Wong CW, Jin S, Chen J, et al. Predictors for bowel resection and the presence of a pathological lead point for operated childhood intussusception: A multi-center study. J Pediatr Surg 2016; 51: 1998-2000.
21. Johnson B, Gargiullo P, Murphy TV, et al. Factors associated with Bowel Resection among infants with Intussusception in the United States. Pediatr Emerg Care 2012; 28: 529-532.

22. Stringer MD, Pablot SM, Brereton RJ. Paediatric intussusception. BrJ Surg 1992; 79: 867-876. 